\title{
How, When, and Where do Football Players get Injured?: a Descriptive Epidemiological Study on Male Professional Football Players in Spain for Four Seasons
}

\author{
${ }^{1}$ Pedro Gomez-Piqueras ${ }^{*},{ }^{2}$ Alberto Nájera López, ${ }^{2}$ Jesus Gonzalez-Rubio, ${ }^{2}$ Enrique Arribas, \\ ${ }^{3}$ María del Pilar Sainz de Baranda Andújar
}

${ }^{1}$ Faculty of Education, University of Castilla-La Mancha, Albacete, Spain. ${ }^{2}$ Faculty of Medicine, University of Castilla-La Mancha, Albacete, Spain. ${ }^{3}$ Faculty of Sport Sciences, University of Murcia, San Javier, Spain.

\begin{abstract}
Background. Sports injuries, in addition to the economic cost which they incur for football clubs, appear to be linked to a worse collective performance during the season. Objectives. The aim of this study was to determine the injury incidence in a professional football team during 4 consecutive seasons. Methods. A total of 109 football players aged about $25 \pm 4$ years, having experience in sports from $18 \pm 5$ years, were analysed based on the injuries which they suffered during the training sessions and competition. Based on the recommendations of the International Federation of Football Associations (FIFA), the exact type, severity and duration of football injuries were reported. Results. A total of 251 injuries (62.7 injuries/season and 2.3 injuries/player) were recorded. The incidence during the competition (37.2 injuries/1000h) was higher than that obtained during the training sessions (3.95 injuries/1000h). The injuries of a muscular type were the ones which showed the highest injury incidence (53\% - 3.3 injuries/1000h), where the posterior thigh (19.6\%), the knee (18.3\%) and the groin $(17.4 \%)$ were the most frequently damaged zones. It was found that $14.4 \%$ of the injuries were relapses of injuries suffered previously. Conclusion. The injury incidence detected in Spanish players is within the normal range for professional football players. The highest frequency injury types are muscular injury, closely followed by joint injury. The variables of injury risk were undifferentiated by the level of competition, player's age, position and time of occurrence (month).
\end{abstract}

KEY WORDS: Epidemiology, Injury, Severity, Exposure, Muscle, Joint, Football.

\section{INTRODUCTION}

Football is a sport of contact and collision with high risk of injury occurrence (1). Injuries incur high economic costs for sports teams (2). The family of the injured players, their coaches and sponsors can also be affected by these events (3).

As a result of injuries, the collective training plans of the team may change. This is because the injured player's participation is either completely interrupted or modified. The team suffers a setback consequent upon the alteration of training sessions $(4,5)$.

It is difficult to rule out the occurrence of injuries when participating in sports. Hence, the coaching staff puts measures in place to minimize such occurrences. For this purpose, a meticulous epidemiological analysis of this problem is developed (6). An analysis of the

*. Corresponding Author:

Pedro Gomez-Piqueras

E-mail: dr.pedro.gomez.piqueras@gmail.com 
etiological and contextual factors, surrounding the incidence of injuries, must be studied with the suitable control measures (7).

The occurrence of injuries can be reduced in countries though the rules of the game (8). In a bid to characterize country specific injury profiles, it is necessary to complete regional epidemiological studies (9). More effective preventive programs can be designed from the knowledge obtained from such studies (10).

The objective of this study was to conduct the descriptive analysis of the injuries suffered by a Spanish professional football team during four consecutive seasons. For this purpose, we analysed the total injury incidence which occurred in the training sessions and during competitive matches. As a result of the lack of researches in Spain, which longitudinally analyzed the impact of injuries on a professional football team, this study is regarded as very innovative and enlightening, since it provides valuable information for use in further works.

\section{MATERIALS AND METHODS}

Based on the latest version of the Helsinki Declaration (1975), this study was approved by the Research Ethics Committee of the University of Castilla La Mancha. Informed consent was obtained from each football player included in the study.

Participants. A cohort study was conducted on a Spanish professional football team (Albacete Football Club) during four seasons (2012/13, 2013/14, 2014/15 and 2015/16).

During the first two seasons, the team competed in the Spanish 2nd Division B Football League, while in the two following seasons they competed in a higher level ("Adelante" League -Professional Football League [LFP]).

During the four seasons, the study was taken out on 109 professionals. The total sample's age was $25 \pm 4$ years, with a football experience of $18 \pm 5$ years. With regard to the anthropometric measurements, the height was $178 \pm 6 \mathrm{~cm}$ and the weight was $73 \pm 6 \mathrm{Kg}$, with a fat percentage of 9.9 \pm 0.8 (Faulkner's formula- 4 skinfolds)(11).

From this total sample, 52 players participated in the first two seasons and 57 players in the last two. Having taken into account their player position, the sample was distributed into 14 goalkeepers, 35 defenders, 20 midfielders, 24 wingers and 16 forwards.

On average in each season, they carried out $238.7 \pm 2.2$ training sessions with an approximate duration of 80 minutes and $43.2 \pm$ 1.7 official games among the League, King's Cup and Play-offs.

Data collection. During the time of the study, all the injuries due to the players' participation in the training sessions and competition were recorded. The medical staffs personally attended all the training sessions and was comprised of 4 members (Doctor, Physiotherapist, Physical Trainer and Sports Therapist). The collection an completion of data forms for each recorded injury was done by the team's physiotherapist. This was done only after agreeing on the information about the injury.

Recorded variables and terminology used

Sports injury. Injury is defined as "any physical damage suffered by a player as a result of a football game or training session which resulted to training or competition loss or modification '(7). Likewise, a recurrent injury is defined as an injury of the same type and in the same place as a previously recorded one and which occurs once the player has returned without restrictions to the standard group training session '(7). They were divided into early recurrent injuries (during the two months subsequent to the return), late recurrent injuries (from 2 to 12 months), and delayed recurrent injuries (which have occurred more than one year after the return to the group) (7).

Severity. The severity is defined as the "number of days elapsed since the appearance of the injury up to the return date of the player to the group training session without restrictions " (7). The day on which the injury occurred is called "Day 0 " and it is not calculated at the time of determining the severity of an injury.

The severity is classified in the following categories:

- Minimal injuries: from 1 to 3 days of absence of full sports practice.

- Mild injuries: absence from sports practice from 4 to 7 days.

- Moderate injuries: absence from sports practice from 8 days up to 28 days.

- Severe injuries: absence from sports practice for more than 28 days. 
Exposure. The time in which a player is exposed to the possibility of suffering from an injury event is called "Exposure". It can be differentiated into "exposure to competition "and "exposure to training session "(7). In Figure 1, it is possible to observe the mode in which the calculation is performed for its recording. The time devoted to the warm-up prior to a competitive game was also recorded as exposure to training session. This exposure time permits us to calculate the injury incidence for every $1000 \mathrm{~h}$ of exposure (injuries/1000h).

\begin{tabular}{|c|c|}
\hline $\begin{array}{c}\text { Total exposure time } \\
\text { matches (hours) }\end{array}$ & $\begin{array}{r}\left(\mathrm{N}^{\circ} \text { matches played by the team } \times 11\left(\mathrm{n}^{\circ} \text { players per team }\right)\right. \\
\times 90 \text { (duration in minutes) } / 60\end{array}$ \\
\hline $\begin{array}{c}\text { Total exposure time } \\
\text { training (hours) }\end{array}$ & Total training time $\times$ players who participated in it $/ 60$ \\
\hline
\end{tabular}

Figure 1. Calculation of exposure time matches and training. Total training time is calculated by multiplying the average duration by the number of training sessions + Total Time warmups competition matches.

Injury Classification. The injuries were classified by injury location, type, and mechanism. For this purpose, the OSICS system (Orchard Sports Injury Classification System) which divides the location of an injury into the head/neck, upper extremities, trunk, lower extremities and others was used (12). The injury type was classified into 6 categories (bone, joints, muscle/tendons, contusion, nervous system and others), while the injury mechanism was classified into injuries due to overload (resulting from a repeated micro-trauma, with or without an identifiable traumatic event) or traumatic (resulting from a specific or recognizable event).

Statistical Analysis. The IBM SPSS v.22 software was used for statistical analysis at a significance level of 0.05 . A descriptive analysis of the sample was conducted and the normality was studied for each of the descriptive variables with the Kolmogorov-Smirnov (K-S) test. To establish the differences between groups, ANOVA and Kruskall Wallis tests were applied.
The following variables were also analyzed: team level, type, location severity, production mechanism, player position, player laterality, production time, and recurrent injuries. Contingency tables were prepared with the chisquare test $\left({ }^{2}\right)$, in order to compare the two categories in which the team participated.

\section{RESULTS}

Description per player position. Table 1 presents the average values for each player position and their corresponding statistical value. Once they have been determined, the ANOVA and Kruskall Wallis tests are used to perform a post hoc analysis (Tukey) for the height variable and tests for $U$ pairs of the Mann Whitney test for the age, fat percentage (\%) and experience.

The midfielders and the wingers have a lower age, a lower height and lower number of years of experience in relation to the remaining player position $(p<0.05)$, while the fat $\%$ variable does not present any difference between groups.

Table 1. Descriptive statistics for player position

\begin{tabular}{|c|c|c|c|c|}
\hline & Age (years) & Height $(\mathrm{cm})^{2}$ & Fat $(\%)^{1}$ & Experience (years) \\
\hline Goalkeepers (14) & $27 \pm 5$ & $184 \pm 5$ & $10.0 \pm 0.9$ & $19 \pm 6$ \\
\hline Defenders (35) & $26 \pm 5$ & $181 \pm 5$ & $9.9 \pm 0.9$ & $18 \pm 6$ \\
\hline Midfielders (20) & $23 \pm 3$ & $172 \pm 5$ & $10.1 \pm 0.8$ & $16 \pm 3$ \\
\hline Wingers (24) & $24 \pm 2$ & $173 \pm 4$ & $9.9 \pm 0.7$ & $16 \pm 3$ \\
\hline Forwards (16) & $28 \pm 4$ & $179 \pm 4$ & $9.8 \pm 0.6$ & $20 \pm 4$ \\
\hline$p$ & $.002 *$ & $.000 *$ & .813 & $.001 *$ \\
\hline
\end{tabular}


Injuries. As indicated above, 109 subjects participated in this study for 4 consecutive seasons. A total of 251 injuries were recorded, which represents an average of 62.7 injuries per season and 2.3 injuries per player.

The total absence days were 3291 with an average of 822.7 days per season. A severity of 30.1 days corresponded to each player, while each injury supposed an average of 13.1 days.

93.6\% of the players suffered injuries. There were only 7 players who did not suffer any injury $(6.4 \%)$.

Injury Incidence (IL). The record of total exposure (the sum of the training sessions and games) represented $39.259 \mathrm{~h} .92 .6 \%$ of this time (36.388h) was devoted to training sessions while $7.4 \%(2.871 \mathrm{~h})$ was for competition.

When associating the total injuries (251) with the exposure hours, we obtained a value of 6.4 injuries/1000h of exposure. Accordingly, 107 (42.6\%) injuries took place in competition and
$144(57.4 \%)$ during the training sessions, where their incidences were 37.2 injuries/1000h and 3.95 injuries/1000h respectively.

Type and Location. The majority of the recorded injuries were muscle/tendon type $(53 \%)$ and joint $(29.9 \%)$ (Table 2).

In relation to its location, the group of lower limbs was the zone which suffered the highest number of injuries, with a percentage of $91.6 \%$. Within location, the posterior thigh region showed a higher percentage than the rest $(19.6 \%)$, followed by the knee $(18.3 \%)$ and groin (17.4\%) (Table 3). The knee injuries, with an average of 23.4 absence days, presented the highest severity (Figure 2). If the injuries are examined based on their laterality, it would be observed that 140 injuries $(55.8 \%)$ occurred in the dominant leg, $86(34.3 \%)$ in the nondominant leg and 25 (10\%) did not show laterality.

Table 2. Injuries Type

\begin{tabular}{|c|c|c|}
\hline \multicolumn{2}{|c|}{ Type (OSICS) } & Incidence \\
\hline Bone & $12(4.8 \%)$ & 0.3 injuries $/ 1000 \mathrm{~h}$ \\
\hline Joint & $75(29.9 \%)$ & 1.9 injuries/1000 h \\
\hline Muscle / Tendon & $133(53.0 \%)$ & 3.3 injuries/1000 h \\
\hline Contusion & $27(10.8 \%)$ & 0.6 injuries $/ 1000 \mathrm{~h}$ \\
\hline Nervous System & $2(0.8 \%)$ & 0.05 injuries $/ 1000 \mathrm{~h}$ \\
\hline Others & $2(0.8 \%)$ & 0.05 injuries $/ 1000 \mathrm{~h}$ \\
\hline Total & $251(100 \%)$ & 6.4 injuries $/ 1000 \mathrm{~h}$ \\
\hline
\end{tabular}

Table 3. Injuries and absence days for lower limb

\begin{tabular}{cccc}
\hline & $\mathrm{N}^{\circ}$ Injuries (\%) & Total Absence Days & Absence days / injury \\
\hline Posterior Thigh & $45(19.6 \%)$ & 654 & 14.5 \\
Knee & $42(18.3 \%)$ & 983 & 23.4 \\
Groin & $40(17.4 \%)$ & 527 & 13.1 \\
Ankle & $38(16.5 \%)$ & 237 & 6.2 \\
Anterior Thigh & $34(14.8 \%)$ & 365 & 10.7 \\
Leg & $13(5.7)$ & 85 & 6.5 \\
Hip & $12(5.2 \%)$ & 97 & 8.0 \\
Foot & $6(2.6)$ & 20 & 3.3 \\
\hline Total & $\mathbf{2 3 0}$ & $\mathbf{2 9 6 8}$ & $\mathbf{1 2 . 9 0}$ \\
\hline
\end{tabular}

Based on severity. A study of the injury's severity determined that the minimal injuries were the most frequent $(34.7 \%)$, followed by the moderate $(32.7 \%)$ and mild injuries $(22.3 \%)$. The least frequent injuries were the severe ones (10.4\%). The injury incidence (II) for the different severities revealed the following results: $\quad \mathrm{II}_{\text {Slight }}=2.21 / 1000 \mathrm{~h}$; $\mathrm{II}_{\text {Minor }}=1.42 / 1000 \mathrm{~h} ; \quad \quad \mathrm{II}_{\text {Moderate }}=2.08 / 1000 \mathrm{~h}$; $\mathrm{II}_{\text {Severe }}=0.66 / 1000 \mathrm{~h}$. 


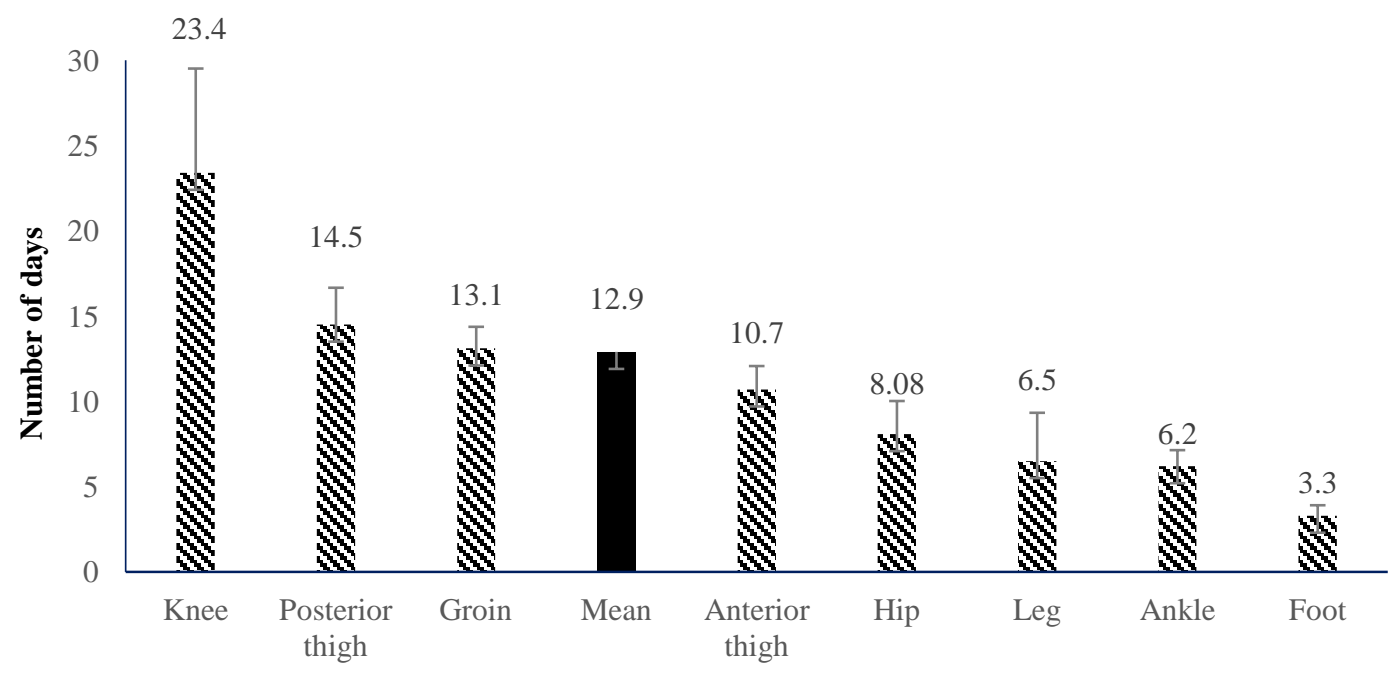

Figure 2. Absence average days per injury.

Based on the production mechanism. $65.7 \%$ of the injuries were traumatic resulting in a recognizable event while $34.3 \%$ appeared to be due to overload. Within the traumatic injuries, a differentiation was made between those which occurred due to direct contact $(48.4 \%)$ and without contact $(51.6 \%)$.

Based on player position. Taking into account the player position of the injured football players, it was found that the defenders (27.9\%) and wingers (27.5\%) showed a higher injury frequency than the rest of the positions: midfielders (19.5\%), forwards $(19.1 \%)$ and goalkeepers $(6.0 \%)$. If the number of injuries suffered per player position is associated with the number of subjects for each group, it was detected that the forwards (3.0 injuries/player), wingers $\quad(2.8$ injuries/player) and midfielders (2.45 injuries/player) showed higher values than the defenders (2 injuries/player) and goalkeepers (1.07 injuries/player).

Based on the moment of appearance (month). The months of June and July showed lower values of injury frequency, due to their lower exposure to injury frequency. The months of October (15.1\%) and April (10.4\%) are the months which showed the highest percentage. The remaining months had similar values.
Based on the moment of appearance (day of the week). When analysing the injuries which occurred in relation to the day of their appearance, we observed the existence of two clearly differentiated peaks: Wednesday $(20.3 \%)$ and Sunday (35.5\%).

Based on the age. The age group (23-28 years old) was the group which showed the highest injury percentage $(58.2 \%)$, followed by the 17-22 age group (25.9\%) and those aged +28 $(15.9 \%)$. If we associate the number of injuries with the number of subjects for each age group, we detected the following result: 23-28 age group (2.4 injuries/player), the 17-22 age group ( 2.1 injuries/ player), and the +28 age group ( 2 injuries/player).

Based on the appearance of recurrent injury. $14.4 \%$ of all the injuries $(\mathrm{N}=36)$ had a recurrent nature. $61.1 \%$ of them occurred in the two months after the football player's return (early recurrent injury) and 38.9\% between 2 and 12 months (late recurrent injury). No delayed recurrent injury (more than 12 months) was detected.

By competitive category. If we compare the obtained data based on the competitive level of the players, similar values were obtained for the total number of injuries suffered (125 injuries for the 2nd B Division League and 126 injuries for the 2 nd 
Professional Football League (LFP)). The absence days were higher for the higher competitive level (1859 compared with 1432).

When seeking differences between groups in relation to the severity variable, we verified that the minimal injuries were higher for the 2 nd $\mathrm{B}$ Division category. It was also verified that the moderate injuries were higher in the 2nd LFP $(p<0.05)$. No differences were detected when making contingencies between level and location.

\section{DISCUSSION}

The injury incidence detected in this study (6.4 injuries/1000h) is similar to the values obtained in the review carried out in 2010 (13), which analysed 33 works published between 1996 and 2007. This review described a total injury incidence for the football teams which fluctuated between 1.1 and 9.4 injuries/1000h of exposure.

In another longitudinal and relevant work (14), the injury incidence was analysed during 7 consecutive seasons in 23 high level football teams selected by the UEFA. The authors described a slightly higher incidence than the one presented here ( 8 injuries/1000h). By performing an analysis of the incidence in other European countries, it will be possible to determine how the incidence recorded in this study (6.4 injuries/1000h) is lower, compared to other countries like Denmark (14.4 injuries / 1000h) (15), Iceland (12.4 injuries / 1000h) (16), Sweden (7.6 injuries / 1000h) (17), or Kosovo (7.4 injuries/1000h) (9). The "northern bias" may serve as an important explanation for this observation of low injury incidence in Spain (teams from regions with Mediterranean type of climate have a lower injury incidence) (8).

By differentiating between competition and training sessions, we verified how the values shown here (37.2 injuries/1000h and 3.9 injuries $/ 1000 \mathrm{~h}$ respectively), determined a higher risk during the competition than during the training sessions. These values can also be framed in the margins provided by the earlier mentioned review (12.7 to 68.7 injuries/1000h of competition and 2.3 to 7.6 injuries/1000 $\mathrm{h}$ of training sessions) (13). The competition has higher physical demands than during the training sessions (18) and this could be among the reasons for a higher injury incidence. Also, during competition, emotional differences may result to differences in this regard (19).

In relation to the type of injury, as confirmed by the review carried out by Noya (20), the muscular injury, closely followed by the joint injury, are the types of injury which occur with the highest frequency. In relation to the damage location, it was described that $91.6 \%$ of the injuries appear in the lower limbs. By reviewing the literature, it was verified that $72 \%-89 \%$ is also located in the lower body (20-23). The thigh, knee and ankle, with percentages ranging from 20 to $28 \%$, are the most frequently damaged zones, followed by the hip and groin with somewhat lower percentages $(13,20,24,25)$. These results are in harmony with our findings where the injuries are located predominantly in the thigh $(34.4 \%)$, knee $(18.3 \%)$ and groin $(17.4 \%)$. Taking into account that the thigh, according to the review, is the zone with the highest injury incidence, it is interesting to mention that its posterior zone, with a percentage of $67 \%$, suffers more injuries than the anterior zone $(20,26)$. In this study, regarding this tendency, the differences were lower between the posterior zone $(56.9 \%)$ and the anterior zone $(43.1 \%)$. The anatomical and functional stress demanded of the players (27), combined with the constant and stressful changes of direction which this sport requires $(28,29)$, explains why the majority of injuries take place in the running muscles and the support joints.

In relation to injury severity, the same as in the other studies $(5,20,23,30)$, it was confirmed that the injury frequency decreases with increasing injury severity. In football training sessions, minor injuries such as bumps and muscle overload are quite common.

With respect to the injury mechanism, our data indicate that $65.7 \%$ of the injuries were traumatic resulting from a recognizable event while $34.3 \%$ appeared due to overload. All the studies in this sense coincide that the majority of injuries that take place in this sport are caused by a traumatic mechanism, with 
percentages comprised between $63 \%$ and $84 \%$ (20).Within these injuries, we differentiate between the ones which occur due to contact (with another player or with the ball) and those which occur without contact, where the latter are more frequent with percentages higher than $50 \%$ in the analysed studies $(20,26)$.In our study, the percentages were almost evenly distributed: direct contact (48.4\%) and without contact $(51.6 \%)$.

The analysis of the player position as a predisposing factor of injury in the performed reviews do not permit the contribution of conclusive data. In turn, there are studies $(2,20)$, which indicate a higher injury incidence in the forwards, and experiences from other authors who do not manage to find axiomatic variations in this regard $(9,31,32)$. In our case, there is a higher tendency for the player to suffer an injury when occupy an offensive position (winger or forward) with values of 2.8 injuries/player and 3 injuries/player respectively. In reference to the player position of the goalkeeper, similar results were found compared to the majority of the studies: the goalkeeper position is the one that presents a lower risk (1 injury/player). A reason for these data could be the higher physical demands covered during matches by offensive players (33).

In relation to the time of the injury, the first months of the season showed a higher quantity of injuries (26). In our case, we cannot discuss a clearly defined tendency throughout the season, with a maximum peak in October and an incidence relatively maintained in the remainder. In Spain, the increase in injuries could be as a result of the climatic change that occurred in October. To verify this hypothesis, more studies of this type are required.

If we focus on the day of the week, we detect two clearly differentiated peaks which correspond to the common day with the highest training load and with the most frequent day of the competition (Wednesday and Sunday).

The findings regarding the relation between injury and age have shown contradictory results. While several authors detected a higher risk of injury in relation to the older age $(1,34)$, other failed to detect anything in this aspect (32). In our context, the differences detected between the three defined age groups (ages 17-22, ages 23-28 and ages over 28) did not seem relevant since they are all found within a range of 2.0-2.4 injuries/player.

In reference to the laterality, we confirmed the slightly higher injury predisposition of the dominant side $(55.8 \%)$ compared to the nondominant side $(44.2 \%)$, which agrees with other experiences $(13,20,35)$. Since the dominant leg is preferentially used for kicking, pushing off, jumping or landing, it could be at increased risk of injury (33).

Injuries which manifest as a result of recurrence show a percentage interval from 7 to $35 \%$ of appearance (20), which is framed within the $14.4 \%$ shown in our experience. In the last few years, these percentages have been reduced as a result of the detailed knowledge now available about injuries and recovery (36).

Finally, a comparison of the severity results in relation to the category of the subjects (2nd Division A or B) showed significant differences between the minor and moderate injuries, where the first was higher and the second was lower for the 2nd Division B category. When relating category and type, no significant differences were found for any of the types. The failure to find data which could contrast our findings or reasons and could explain this phenomenon motivates us to continue the in-depth study of this question for future studies.

The different methodologies used in the studies of this type, primarily in relation to the specification and definition of the main terms, in many cases hinder the comparison of the results. We remind the importance of following the recommendations of the consensus documents published in this regard.

\section{CONCLUSION}

In conclusion, it can be said that the injury incidence detected in this study (6.4 injuries/1000h) is within the normal range for professional footballers. There was a recurrence in $14.4 \%$ of the total cases. The high injury incidence in football as well as the high risk of recurrent injury, require the 
establishment and integration of preventive measures in the training sessions.

Injuries types with highest frequency are muscular injury, closely followed by joint injury. However, the most affected regions are the thigh, knee and groin. The risk of injury could not be differentiated based on the competitive level, age, player position and the moment of appearance (month).

Epidemiological and longitudinal studies in professional contexts provide us with very valuable information for a deep understanding of a complex phenomenon such as sport injury.

\section{APPLICABLE REMARKS}

- Injuries in professional football are a major problem to consider.

- By building up on these findings, future researchers should identify risk factors for the most prevalent injuries. Also, researches should aim at developing prevention programmes.

- Preventive programmes which are specially designed to protect the thigh, knee and groin should be developed and put into practice.

\section{REFERENCES}

1. Arnason A, Sigurdsson SB, Gudmundsson A, Holme I, Engebretsen L, Bahr R. Risk Factors for Injuries in Football. Am J Sports Med. 2004;32(90010):5-16.

2. Giza E, Micheli L. Soccer injuries. Med Sport Sci. 2005;49:140-69.

3. Burgess TL. Ethical issues in return-to-sport decisions. South African J Sport Med. 2011;23(4):138-9.

4. Eirale C, Farooq A, Smiley FA, Tol JL, Chalabi H. Epidemiology of football injuries in Asia: A prospective study in Qatar. J Sci Med Sport. 2013;16(2):113-7.

5. Hägglund M, Waldén M, Magnusson H, Kristenson K, Bengtsson H, Ekstrand J. Injuries affect team performance negatively in professional football: an 11-year follow-up of the UEFA Champions League injury study. $\mathrm{Br} \mathrm{J}$ Sports Med. 2013;47(12):738-42.

6. Goncalves G, Santoro P, Luiz J, Cohen M. The Brazilian Football Association (CBF) model for epidemiological studies on professional soccer player injuries. Clinics. 2011;66(10):1707-12.

7. Fuller CW, Ekstrand J, Junge A, Andersen TE, Bahr R, Dvorak J, et al. Consensus statement on injury definitions and data collection procedures in studies of football (soccer) injuries. Scand J Med Sci Sports. 2006;16(2):83-92.

8. Waldén M, Hägglund M, Orchard J, Kristenson K, Ekstrand J. Regional differences in injury incidence in European professional football. Scand J Med Sci Sports. 2013;23(4):424-30.

9. Shalaj I, Tishukaj F, Bachl N, Tschan H, Wessner B, Csapo R. Injuries in professional male football players in Kosovo: a descriptive epidemiological study. BMC Musculoskelet Disord. BMC Musculoskeletal Disorders; 2016;17:338.

10. Owoeye O, Akinbo S, Olawale O, Tella B, Ibeabuchi N. Injury prevention in football: Knowledge and behaviour of players and availability of medical care in a Nigerian youth football league. South African J Sport Med. 2013;25(3):77.

11. Faulkner J. Physiology of swimming and diving. Human exercise physiology, editor. Baltimore: Academic Press; 1968.

12. Rae K, Orchard J. The Orchard Sports Injury Classification System (OSICS) Version 10. Clin J Sport Med. 2007;17(3):201-4.

13. Llana S, Pérez P, Lledó E. The epidemiology on soccer: a systematic review. Rev Int Med y Ciencias la Act Fis y del Deport. 2010;10:22-40.

14. Ekstrand J, Hägglund M, Waldén M. Injury incidence and injury patterns in professional football: the UEFA injury study. Br J Sports Med. 2011 Jun;45(7):553-8.

15. Hägglund $\mathrm{M}$, Waldén M, Ekstrand J. Injury incidence and distribution in elite football - A prospective study of the Danish and the Swedish top divisions. Scand J Med Sci Sport. 2005;15(1):21-8.

16. Arnason A, Gudmundsson A, Dahl HA, Jóhannsson E. Soccer injuries in Iceland. Scand J Med Sci Sports. 1996;6(1):40-5.

17. Hägglund M, Waldén M, Ekstrand J. Previous injury as a risk factor for injury in elite football: a prospective study over two consecutive seasons. Br J Sports Med. 2006;40(9):767-72.

18. Condessa LA, Cabido CET, Lima AM, Coelho DB, Rodrigues VM, Chagas MH, et al. Analysis and comparison of intensity in specific soccer training sessions. Mot Rev Educ Física. Motriz: revista de educação física. 
2015;21(1):54-60.

19. Alix-Sy D, Le Scanff C, Filaire E. Psychophysiological responses in the pre-competition period in elite soccer players. J Sports Sci Med. 2008;7(4):446-54.

20. Noya Salces J, Gómez-Carmona PM, Gracia-Marco L, Moliner-Urdiales D, Sillero-Quintana M. Epidemiology of injuries in First Division Spanish football. J Sports Sci. 2014;32(13):1263-70.

21. Fuller C, Drawer S. The application of risk management in sport. Sports Med. 2004;34(6):349-56.

22. Junge A, Dvorak J. Soccer injuries: a review on incidence and prevention. Sport Med. 2004;34(13):929-38.

23. Waldén M, Hägglund M, Ekstrand J. UEFA Champions League study: a prospective study of injuries in professional football during the 2001-2002 season. Br J Sports Med.2005;39(8):542-6.

24. Akodu AK, Owoeye OBA, Ajenifuja M, Akinbo SRA, Olatona F, Ogunkunle O. Incidence and characteristics of injuries during the 2011 West Africa Football Union (WAFU) Nations' Cup. Afr J Med Med Sci. 2012;41(4):423-8.

25. Mallo J, González P, Veiga S, Navarro E. Injury incidence in a Spanish sub-elite professional football team: A prospective study during four consecutive seasons. J Sports Sci Med. 2011;10(4):731-6.

26. Hawkins RD, Hulse M a, Wilkinson C, Hodson A, Gibson M. The association football medical research programme: an audit of injuries in professional football. Br J Sports Med. 2001;35(1):43-7.

27. Rienzi E, Drust B, Reilly T, Carter JE, Martin A. Investigation of anthropometric and work-rate profiles of elite South American international soccer players. J Sports Med Phys Fitness. 2000;40(2):162-9.

28. Chaouachi A, Manzi V, Chaalali A, Wong DP, Chamari K, Castagna C. Determinants Analysis of Change-ofDirection Ability in Elite Soccer Players. J Strength Cond Res. 2012;26(10):2667-76.

29. Ortega DR, Rodríguez Bíes EC, Berral de la Rosa FJ. Analysis of the vertical ground reaction forces and temporal factors in the landing phase of a countermovement jump. J Sports Sci Med. 2010;9(2):282-7.

30. Hägglund M, Waldén M, Ekstrand J. Previous injury as a risk factor for injury in elite football: a prospective study over two consecutive seasons. Br J Sports Med. 2006;40(9):767-72.

31. Chomiak J, Junge A, Peterson L, Dvorak J. Severe injuries in football players. Influencing factors. Am J Sports Med. 2000;28(5 Suppl):S58-68.

32. Morgan BE, Oberlander MA. An examination of injuries in major league soccer. The inaugural season. Am $\mathbf{J}$ Sports Med.2001;29(4):426-30.

33. Suarez-Arrones L, Torreño N, Requena B, Sáez De Villarreal E, Casamichana D, Barbero-Alvarez JC, et al. Match-play activity profile in professional soccer players during official games and the relationship between external and internal load. J Sports Med Phys Fitness. 2015;55(12):1417-22.

34. Ostenberg A, Roos H. Injury risk factors in female European football. A prospective study of 123 players during one season. Scand J Med Sci Sports. 2000;10(5):279-85.

35. Woods C, Hawkins RD, Maltby S, Hulse M, Thomas A, Hodson A, et al. The Football Association Medical Research Programme: an audit of injuries in professional football--analysis of hamstring injuries. Br J Sports Med. 2004;38(1):36-41.

36. Hägglund M, Waldén M, Ekstrand J. Injury recurrence is lower at the highest professional football level than at national and amateur levels: does sports medicine and sports physiotherapy deliver? Br J Sports Med. 2016;50(12):bjsports-2015-095951. 